\title{
Remarks on Book the Study of Language by George Yule
}

\author{
Dan Liu \\ School of Marxism, School of Politics and Law, Sichuan University of Arts and Science, \\ Dazhou635000, China \\ 763927243@qq.com
}

Keywords: linguistics, second language learners, remarks.

\begin{abstract}
Linguistics is a crucial academic discipline in terms of English teaching. There is no doubt the knowledge of linguistics means a lot to second language learners. Furthermore, foreign language teachers attach more importance to the study of Linguistics. Language, the carrier of culture system has been researched extensively over the years. The publication of The Study of Language in 2000 by George Yule who was an American linguist aroused a world-wide interest among scientists, especially linguists. This thesis concentrates on the reviews based on the book The Study of Language written by George Yule.
\end{abstract}

\section{Introduction}

The Study of Language written by George Yule is a classical literature of Contemporary Foreign Linguistics. and Applied Linguistics. It is available to foreign language teachers and postgraduate of linguistics. To date, this book as a representative selection covers the most significant branches of linguistic studies. Furthermore, scholars have recognized it as leading authority in the field of linguistics. The availability of numerous materials in linguistics will greatly help foreign language teachers and second language learners to foster their own understanding of linguistics. Above all, this book means a lot to the development of linguistics as a discipline in Chinese universities. The book is highly commended by foreign language learners for obtaining sin sight into the essence of language from both a theoretical and a practical view. It exerts a great influence over the study of some concrete languages and accelerates the study of linguistics in China.

\section{Aspects for Evaluating This Book}

\subsection{Aims}

After reading, we can build up the basic knowledge of linguistics. We have the ability to comprehend the essence of the linguistics. What's more, the book presents theoretical basis for cultivating basic foreign language teaching skills.

\subsection{Design and Organization}

In my view, this book is well-organized since it provides an overall description to the study of linguistics and greatly facilitate foreign language learners to build up basic knowledge of linguistics. It also presents numerous primary aspects about linguistics that we should master as English majors. To a large extent, it lays a solid foundation for foreign language learners in all the essential subsystems of linguistics.

21 chapters are presented in total. The contents give us a clear typesetting and we can get a main structure easily. In the part of introduction, we can obtain the main ideas of each chapter based on the Chinese translation of English contents. In the preface, the primary information of this book is addressed by the author in order to help readers to find a clear direction. The introduction of each chapter is "excerpt from the classics" which are specially selected as a way to help readers understand the content of the chapter more deeply such as: G. Leech (1983), P. Brown and S. Levinson (1987), H. Sacks (1992), J. Thomas (1995) .In each chapter, some vivid pictures are cited to accelerate readers learning motivation and help them to comprehend smoothly. Chinese translation of the main idea in each chapter has been presented in the beginning of this book so as to provide learners a clear 
understanding. Each chapter has a topic related to linguistics. They are all the basic aspects of linguistics. Some topics are easy to figure out but others are stubborn. For example, language and machines of chapter fourteen is awkward for me to understand. I am confused how the computer codes the language systematically. In a word, the topics are comprehensive for most foreign language learners. In each chapter, plenty of study questions and discussion topics are remained to check whether readers have understood the main points or not. In the part of further reading, we can also broad our horizon and get more relative information through referring to more related literature. More specifically, there are many pictures, diagrams, illustrations, and examples that give us a better understanding of the related topics. In the index, technical terms and page references where definitions can be found are indicated by bold type in order to give readers a clear typesetting. In other words, readers can look it up to clear their confusions according to the page number.

\subsection{Main Contents}

This book probes into the most crucial aspects of linguistics: the essence and subsystems of language based on the book .It explores quite a few questions: the origins of language, the development of writing, the properties of language, animals and human language, the sounds of language, the sound patterns of language, words and word-formation processes, morphology, phrases and sentences, syntax, semantics, pragmatics, discourse analysis, language and machines, language and brain, first/second language acquisition, sign language, language history and change, language varieties, and the relationship among language, society, culture as well.

More specifically, the following confusions have been cleared up by the book: how conversation takes place, how children learn language in the critical period, why children learn language quickly than the adults, why women and men speak differently, how language varies between regions, and how social factors influence language and culture. However, I am confused with abstract Phonetics and Phonology. Yule argues the point of investigating phonological processes is not to arrive at a set of rules about how a language should be pronounced, but to try to come to an understanding of the regularities and patterns which underlie the actual use of sounds in language(Yule,2000).As to grammar in the chapter nine, he also holds the view of grammar as a set of rules for the 'proper' use of a language is still to be found today and may be best characterized as the prescriptive approach(Yule,2000).Most importantly, the generative grammar mentioned by Noam Chomsky in the chapter ten. He holds that "I will consider a language to be a set (finite and infinite) of sentences (Chomsky, 1957).What is more, discourse analysis is stubborn for me in the chapter thirteen. Grice (1975) argues: "Make your conversational contribution such as is required, at the stage at which it occurs, by the accepted purpose or direction of the talk exchange in which you are engaged." All the subsystems of language lay a solid foundation for second language acquisition and linguistic studies.

\subsection{Methodology}

Audio-lingual method, communicative approach, grammar-translation method, student centered method. All the methodologies are used in the book. Usually, the student centered method and grammar-translation method are common in the foreign language teaching. Situational method is not used in the book.

\subsection{Skills}

We can learn more about the basic contents of the linguistics. Some language learning skills will be enhanced. We can gain reading strategies and writing skills after reading.

\subsection{Guiding Ideology}

It provides a comprehensive introduction to the study of language. It is essential for postgraduates majoring in English teaching. To some extent, this book is very important for both students and teachers.

\subsection{Language Material}

The materials in this book are easy to teach and learn. It can be used with little preparation. Maybe some chapters are not practical and can hardly figure out. It provides authentic cultural information about the nature of the language. Numerous materials in this book will greatly help students to build up their own knowledge of the topics and know the essence of language from a theoretical point of view. 


\subsection{Components}

E-books, PPT slides, pictures, exercise books. All the components can provide the students with a comprehensive learning ways. In other words, the students will be motivated. Materials, pictures, graphs which can be selected to illustrate many aspects of the language including culturally based practices and beliefs. It relates more closely to learners' needs. This book have a positive effect on learners' motivation because there is a huge supply of interesting sources, pictures and materials for language learning in each chapter.

\section{Conclusion}

All in all, This textbook is excellent in linguistics because it matches the needs of foreign language teachers and postgraduate students majored in linguistics and English education. In my view, language can reflect thoughts, concerns and transmit culture. In a word, we can't live without language. Of course, as an introduction to the nature of the linguistics, the book also has some limitations due to space limitations. The book also does not discuss the topic of linguistics that has attracted more attention in recent years such as activity types, discourse roles, pragmatic ambivalence and so on.

From the macro and micro perspective, this book gives us clear basic contents of the linguistics that we should know as English majors. After reading, I can have a better understanding about the nature of language. There are some aspects I am still confused such as language and machines. I need do more research and read more related literature to figure it out. Lastly, more researches are needed in this regard, which is also the high expectations that the author gives to readers at the end of the book.

\section{References}

[1]. Yule, G. The Study of Language [M].the Press of the University of Cambridge, 2000.

[2]. Chomsky, N. Syntactic Structure [M]. Mouton: The Hague, 1957.

[3]. Grice, H. P. Logic and Conversation. Syntax and Semantics 3[M].Speech Acts Academic Press, 1975.

[4]. Leech, G. Principles of Pragmatics [M].Long-man, 1983.

[5]. Brown, P. and Levinson, S. Politeness: Some Universals of Language Usage [M].CUP, 1987.

[6]. Sacks, H. Lectures on Conversation [J]. Vols. 1- 2, Blackwell,1992.

[7]. Thomas, J. Meaning in Interaction: An Introduction to Pragmatics [M].Longman, 1995. 